DOI: https://doi.org/10.47405/mjssh.v5i12.589

\begin{tabular}{|c|c|}
\hline 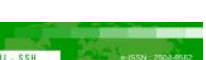 & Malaysian Journal of Social Sciences and Humanities (MJSSH) \\
\hline Malaysian Journal of & Volume 5, Issue 12, December 2020 \\
\hline (MJ-sSH) & e-ISSN : 2504-8562 \\
\hline & $\begin{array}{l}\text { Journal home page: } \\
\text { www.msocialsciences.com }\end{array}$ \\
\hline
\end{tabular}

\title{
Menyingkap Peristiwa Penyingkiran Singapura dari Malaysia (1963-1965)
}

\author{
Mohd Sohaimi Esa1, Romzi Ationg1 \\ 1Pusat Penataran Ilmu dan Bahasa, Universiti Malaysia Sabah (UMS) \\ Correspondence: Mohd Sohaimi Esa (msohaimi@ums.edu.my)
}

\begin{abstract}
Abstrak
Sebaik sahaja penubuhan Malaysia, pemimpin Persekutuan yang diterajui oleh Tunku Abdul RahmanTun Razak bukan sahaja terpaksa berhadapan dengan konfrontasi Malaysia-Indonesia, tetapi juga masalah Singapura yang dicetuskan oleh Lee Kuan Yew. Lee Kuan Yew terus menerus mencetuskan provokasi dan tekanan kepada kerajaan pusat sehingga membawa kepada penyingkiran Singapura dari Malaysia. Justeru itu, tidak hairanlah sekiranya salah seorang pemimpin utama Persekutuan, Timbalan Perdana Menteri Tun Abdul Razak menganggap Singapura seumpama, 'duri dalam daging' selama berada dalam Malaysia. Persoalannya, mengapakah beliau mengungkapkan perumpamaan tersebut? Kertas kerja ini akan menyingkap peristiwa penyingkiran Singapura dari Malaysia (1963-1965), terutamanya dalam aspek peranan yang dimainkan oleh Tun Razak dalam usaha meleraikan isu berkaitan Singapura semasa dalam Persekutuan Malaysia.
\end{abstract}

Kata Kunci: pemimpin persekutuan, Tun Razak, Singapura, Lee Kuan Yew

\section{Unveiling the Incident of Singapore Separation from Malaysia (1963-1965)}

\begin{abstract}
Quickly after the formation of Malaysia, the federal leaders led by Tunku Abdul Rahman-Tun Razak had not only dealing with the Malaysia-Indonesia confrontation, but also the problem relating to Singapore ignited by Lee Kuan Yew. Lee Kuan Yew had continuously triggering provocation and pressure. Thus, it was not a surprise when one of the federal governments, the Deputy Prime Minister, Tun Abdul Razak described Singapore as a 'torn in a flesh' while it part of Malaysia. But why he described Singapore as such? This paper unveils the incident of Singapore expulsion from Malaysia (1963-1965), especially in the context of role played by Tun Razak in overcoming issues relating to Singapore when it was part of Malaysian Federation.
\end{abstract}

Keywords: federal leadership, Tun Razak, Singapura, Lee Kuan Yew

\section{Pendahuluan}

Sebaik sahaja penubuhan Malaysia, pemimpin Persekutuan yang diterajui oleh Tunku Abdul RahmanTun Razak bukan sahaja terpaksa berhadapan dengan konfrontasi Malaysia-Indonesia, tetapi juga masalah Singapura yang dicetuskan oleh Lee Kuan Yew. Lee Kuan Yew terus menerus mencetuskan 
provokasi dan tekanan kepada kerajaan pusat sehingga membawa kepada penyingkiran Singapura dari Malaysia. (Mohd Sohaimi, 2011) Justeru itu, salah seorang pemimpin utama Persekutuan, Timbalan Perdana Menteri Tun Abdul Razak menganggap Singapura seumpama, 'duri dalam daging' selama berada dalam Malaysia. Persoalannya, mengapakah beliau mengungkapkan perumpamaan tersebut? Justeru itu, kertas kerja ini akan membincangkan kedudukan dan peranan yang dimainkan oleh Tun Razak dalam usaha meleraikan isu Singapura dalam Persekutuan Malaysia. Bagi tujuan tersebut kaedah analisis bahan sejarah iaitu salah satu kaedah yang sering digunakan dalam penyelidikan sejarah. Kaedah ini, sebagaimana yang dinyatakan oleh Ahmad Tarmizi, Romzi dan Nurul (2017) merupakan kaedah kajian kualitatif yang bertujuan mengetahui peristiwa lama yang berkait rapat dengan pelbagai aspek seperti peranan seseorang pemimpin dan isu lain yang dianggap berkaitan. Dalam masa yang sama Romzi (2017) juga menjelaskan bahawa kaedah seumpama ini bukan hanya mampu memberi gambaran jelas tentang sesuatu peristiwa tetapi juga menyumbang kepada perolehan maklumat yang bertujuan memperkayakan lagi sesuatu kajian. Oleh yang demikian, adalah jelas bahawa penggunaan kaedah analisis bahas sejarah adalah bertepatan dengan usaha untuk menjawab personal berkenaan peristiwa penyingkiran Singapura dari persekutuan Malaysia dengan memberi penekanan terhadap terutamanya dalam aspek peranan yang dimainkan oleh Tun Razak dalam usaha meleraikan isu berkaitan Singapura semasa dalam Persekutuan Malaysia.

\section{Tun Razak dalam Menangani Masalah Singapura}

Tunku Abdul Rahman-Tun Razak sebagai pemimpin utama Malaysia terpaksa berhadapan dengan masalah dalam negara apabila Singapura menimbulkan konflik dengan kerajaan pusat, Kuala Lumpur. Lee Kuan Yew, Ketua Menteri Singapura terus menimbulkan provokasi apabila membantah penangguhan tarikh pengisytiharan Malaysia dari 31 Ogos kepada 16 September 1963. Tarikh perisytiharan Malaysia pada 31 Ogos 1963 terpaksa ditangguhkan bagi membolehkan Rombongan Sekretariat PBB di bawah Lawrence Michelmore untuk melakukan referendum ke atas penduduk Sabah dan Sarawak. Keputusan penghantaran rombongan itu telah dibuat bagi memenuhi keputusan Persidangan Manila yang telah ditandatangani oleh Tun Razak dengan Menteri Luar Indonesia dan Filipina (Means, 1970). Beliau bertegas untuk meneruskan pengisytiharan kemerdekaan Singapura pada 31 Ogos 1963 sepertimana yang diputuskan dalam Rundingan London. Walaupun dijemput, Tun Razak enggan hadir dalam perisytiharan kemerdekaan Singapura itu. Lee Kuan Yew mengakui beliau mengisytiharkan sendiri kemerdekaan Singapura pada 31 Ogos 1963. Sementara wakil kerajaan British, yakni Duncan Sandys juga tidak hadir dalam perisytiharan tersebut. (Lee Kuan Yew, 2000). Pada dasarnya, perisytiharan kemerdekaan secara unilateral oleh Lee Kuan Yew itu telah memeranjatkan Tunku Abdul Rahman dan Tun Razak (PREM 11/4351, Kuala Lumpur - Singapura, 2 September 1963). Bagi Tun Razak, beliau sememangnya kurang senang dan tidak percaya dengan Lee Kuan Yew sejak Rundingan London lagi. Kini apa yang dikhuatiri oleh Tun Razak menjadi kenyataan. Perasaan ini pernah dikongsi bersama dengan pemimpin MCA, Tan Siew Sin dan Tunku Abdul Rahman sebelum pengisytiharan Malaysia lagi. (DO 187/30, Talks in London on the Establishment of the Federation of Malaysia, June-July 1963).

Pada 2 September, Tun Razak menghadiri mesyuarat Kabinet Kerajaan Persekutuan untuk membincangkan tindak tanduk Lee Kuan Yew yang mengisytiharkan lebih awal kemerdekaan Singapura. Kabinet memutuskan bahawa tindakan kerajaan Singapura itu sebagai tidak sah dan tidak berperlembagaan. Kabinet juga membuat keputusan untuk mengemukakan surat bantahan kepada kerajaan British atas tindakan Lee Kuan Yew itu (PREM 11/4351, Kuala Lumpur - Singapura, 2 September 1963). Sementara Lee Kuan Yew pula tidak melayani bantahan tersebut, malah beliau menganggapnya sebagai "salah satu perkara yang menyedihkan" atas tindakan kerajaan persekutuan terhadap Singapura” (Lee Kuan Yew, 2000; Straits Times, 4 September 1963).

Pada 3 September 1963, Lee Kuan Yew sekali lagi melakukan tindakan yang kurang menyenangkan kerajaan Persekutuan apabila membubarkan Majlis Legislatif Singapura dan mengisytiharkan tarikh penamaan calon pilihan raya pada 12 September. Langkah ini dilakukan dengan muslihat untuk mengukuhkan lagi kedudukan Lee Kuan Yew dan PAP dalam politik Singapura (Ratnam \& Milne, 1967). Sungguhpun begitu, keputusan untuk mengadakan pilihan raya secara tergesa-gesa ini 
dikatakan mempunyai hubungannya dengan saranan Tun Razak untuk mengatasi dan menyekat pengaruh Lee Kuan Yew itu. Tun Razak pernah berkata kepada Lord Selkirk beberapa bulan sebelum penubuhan Malaysia bahawa kemungkinan "elections producing an alternative government to replace Lee" (DO 169/19, No. 33/45/1, Selkirk to Secretary of State for the Colonies, (Telegram no. 402), 13 June 1963). Sesungguhnya, kenyataan ini telah membimbangkan Lee Kuan Yew yang sememangnya menunggu masa yang terbaik untuk mengadakan pilihan raya di Singapura (Lee Kuan Yew, 2000).

Sementara pihak British tidak dapat menutup perasaan bimbangnya dengan tindakan Singapura itu. Lantas Geofroy Tory telah mengadakan perbincangan dengan Tun Razak dan Tun Dr. Ismail di Kuala Lumpur pada 5 September. Tun Razak dan Tun Dr. Ismail telah memberikan jaminan kepada pihak British bahawa penubuhan Malaysia tetap diteruskan, walau apa jua yang dilakukan oleh Lee Kuan Yew. Geofroy Tory telah menyampaikan suara jaminan itu kepada Perdana Menteri Britain, Harold Macmillan (Lee Kuan Yew, 2000). Sebenarnya, jaminan itu jugalah yang diharapkan oleh pihak British yang mahukan agar diteruskan rancangan penubuhan Persekutuan Malaysia.

Walau bagaimanapun, keputusan pilihan raya Singapura pada 21 September sungguh mengejutkan Tunku Abdul Rahman-Tun Razak dan pemimpin-pemimpin lain dalam Perikatan. Semua calon UMNO-Perikatan Singapura tewas di tangan calon PAP. PAP telah berjaya mendapat majoriti dengan memperoleh 37 daripada 51 kerusi, Barisan Sosialis pula 13 kerusi dan satu kerusi untuk UPP (United People's Party) (Mohamed Noordin, 1974; Ratnam \& Milne, 1964). Pada dasarnya, impian Tunku Abdul Rahman-Tun Razak untuk melihat UMNO-Perikatan Singapura memerintah pulau itu terus lenyap sama sekali (Nik Anuar, 2001). Peristiwa ini turut memberi kesedaran kepada para pemimpin persekutuan tentang betapa sukarnya kerajaan pusat untuk mengawal dan memimpin politik Singapura. Lee Kuan Yew terus melakukan sandiwara politiknya.

Sebagaimana yang dijangkakan, Lee Kuan Yew terus menimbulkan provokasi apabila mengumumkan hasratnya untuk bekerjasama dengan UMNO. Akan tetapi beliau enggan menyertai Perikatan sekiranya MCA dan MIC terus menjadi anggota Perikatan. Pengumuman Lee Kuan Yew itu kemudiannya diselar oleh Tunku Abdul Rahman yang dianggap tidak bertanggungjawab dengan matlamat untuk memecahbelahkan Perikatan. Tunku Abdul Rahman memberi jaminan bahawa UMNO tetap bersama-sama dengan MCA dan MIC untuk selama-lamanya (The Sunday Times, 29 September 1963; Malay Mail, 30 September 1963; Muhamed Noordin, 1974; Lau, 1998; Chan, 1971). Ikhtibar daripada peristiwa ini juga telah mengukuhkan lagi hubungan UMNO, MCA dan MIC dalam Perikatan.

Selepas lima tahun, Tun Razak dilantik semula sebagai Pengerusi Jawatankuasa Pilihan Raya Perikatan. Sebagai pengerusi, Tun Razak perlu mengatur strategi untuk memastikan kejayaan Perikatan dalam pilihan raya peringkat Persekutuan pada bulan April 1964. Senario yang dilalui kali ini berbeza dengan pilihan raya umum sebelumnya, apabila dengan terbentuknya Persekutuan Malaysia (Romzi, Mohd. Sohaimi \& Mohd. Azri, 2020; Romzi, Mohd Azri, Mohd. Sohaimi \& Madiyem, 2020) maka Perikatan bukan sahaja berhadapan dengan parti-parti pembangkang yang sedia ada, tetapi juga saingan daripada Lee Kuan Yew dan PAP.

Sesungguhnya, bayangan Lee Kuan Yew dan PAP masih lagi menyelubungi para pemimpin Perikatan. Selepas gagal bekerjasama dengan UMNO, Lee Kuan Yew mengambil keputusan untuk mengembangkan sayap PAP di Semenanjung Malaysia Pengumuman ini dilakukan oleh Pengerusi PAP, Toh Chin Chye pada 1 Mac 1964 (The Straits Times, 2 Mac 1964; Muhamed Noordin, 1974; Lau, 1998). Langkah ini dilakukan sebagai persediaan PAP untuk menghadapi pilihan raya umum tersebut (Ratnam \& Milne, 1967). Sebelum pengumuman, Tun Razak telah pun diberitahu secara tidak rasmi hasrat PAP untuk bertanding dalam pilihan raya tersebut oleh Goh Keng Swee pada 29 Februari 1964. Dengan perasaan kecewa, hasrat ini disanggah oleh Tun Razak dengan nada sinis dengan menganggap usaha PAP itu akan gagal (Lau, 1998). Sungguhpun begitu, PAP tetap mahu bertanding dalam pilihan raya tersebut dengan membuat pengumuman rasmi menerusi pengerusinya, Toh Chin Chye pada 1 Mac. Pada dasarnya, tindakan ini bertentangan dengan perjanjian Malaysia, yakni PAP bersetuju untuk tidak akan bertanding dalam pilihan raya di Semenanjung Malaysia (Lau, 1998; Chan, 
1971; Muhamed Noordin, 1974; Turnbull, 1977). Tindakan Lee Kuan Yew ini tentulah menimbulkan perasaan kurang senang dalam kalangan pemimpin Persekutuan.

Semasa berkempen, para pemimpin perikatan telah menyeru penduduk Tanah Melayu agar tidak mengundi PAP. Malah mereka dengan nada tegas mengingatkan bahawa menyokong dasar-dasar yang bercorak perkauman akan menimbulkan kekacauan yang serius (Shaws, 1976). Dalam pilihan raya ini, PAP telah meletakkan sembilan orang calon untuk mencabar MCA. Berdasarkan jumlah calon PAP itu, Tun Razak sebagai Pengerusi Jawatankuasa Pilihan Raya Perikatan tidak begitu bimbang dengan tentangan PAP tersebut. Malahan tugas Tun Razak lebih mudah lagi kerana kempen kali ini lebih berpihak kepada Perikatan berbanding dengan pilihan raya tahun 1959. Konfrontasi MalaysiaIndonesia dijadikan modal utama sewaktu berkempen oleh Tun Razak dan pemimpin-pemimpin lain dalam Perikatan. Semangat patriotik turut disemai dalam kalangan rakyat untuk menolak parti pembangkang yang dikatakan anti-Malaysia, serta menyokong dan bekerjasama dengan Indonesia. (Mohd Sohaimi, 2011)

Ringkasnya, Perikatan menang besar apabila memenangi 89 daripada 104 kerusi peringkat parlimen yang dipertandingkan dalam pilihan raya ini. Jumlah undi untuk Perikatan juga meningkat sebanyak 58 peratus berbanding dengan 52 peratus atau 74 kerusi dalam pilihan raya tahun 1959. PAS pula mengalami kemerosotan apabila hanya memperoleh sembilan kerusi berbanding dengan 13 kerusi yang telah dimenanginya pada tahun 1959. Sementara parti-parti pembangkang lain turut mengalami kemerosotan iaitu Socialist Front (hanya dua kerusi berbanding lapan kerusi) dan People's Progressive Party atau PPP (memenangi dua daripada empat kerusi). Sementara United Democratic Party (UDP) dan People's Action Party (PAP) pula bertanding untuk pertama kalinya di Semenanjung Malaysia, masing-masing mendapat satu kerusi. Parti Negara pula gagal untuk mendapatkan sebarang kerusi dan tiada seorang calon bebas pun yang menang (Malaysia, 1965; Ratnam \& Milne, 1964). Pada dasarnya, keputusan itu boleh dianggap sebagai suatu kejayaan besar kepada Tun Razak yang dilantik sebagai Pengerusi Jawatankuasa Pilihan Raya Perikatan.

Malah lebih membanggakan Tun Razak apabila kemenangan besar Perikatan untuk merampas kembali 15 kerusi kawasan pilihan raya Parlimen yang dahulunya dikuasai oleh parti-parti pembangkang ataupun calon-calon bebas. Begitu juga, tidak ada seorang calon Perikatan pun yang hilang wang pertaruhannya. Seramai 49 calon telah hilang wang pertaruhannya disebabkan mendapat kurang daripada satu perlapan daripada jumlah undi iaitu 14 daripadanya calon UDP, 11 calon PAS, sembilan orang calon Socialist Front, enam orang calon PAP, tiga orang calon Parti Negara, dua calon PPP dan empat calon bebas (Shaws, 1976; Ratnam \& Milne, 1964). Sementara Lee Kuan Yew dan PAP yang menjadi 'musuh ketat' Tun Razak dan Perikatan hanya memenangi sebuah kerusi Parlimen sahaja iaitu kawasan Bangsar (Devan Nair adalah calon PAP di kawasan parlimen Bangsar). PAP juga gagal untuk mendapatkan sebarang kerusi dalam pilihan raya peringkat negeri. Justeru itu, Lee Kuan Yew gagal dalam usahanya untuk mengembangkan pengaruh politik PAP di Semenanjung Malaysia. Tun Razak dan pemimpin-pemimpin Perikatan terus memandang serong kepada Lee Kuan Yew dan PAP (Nik Anuar, 2001; Gullick, 1969).

\section{Menyingkap Peristiwa Penyingkiran Singapura}

Selepas pilihan raya, Tun Razak melihat masalah Lee Kuan Yew dan Singapura itu seolah-olah tidak ada kesudahannya. Beliau sebagai Timbalan Perdana Menteri terus meneliti perkembangan yang berlaku dari semasa ke semasa. Masalah bertambah rumit lagi apabila timbul ketegangan antara orang Melayu dengan pihak kerajaan yang dipimpin oleh Lee Kuan Yew. UMNO Singapura yang sememangnya kurang senang dengan pentadbiran Lee Kuan Yew telah berusaha untuk memperjuangkan hak orang Melayu di pulau itu. Pada awal bulan Mei 1964, UMNO telah mengemukakan bantahan keras kepada kerajaan susulan penduduk Melayu diarah berpindah dari kawasan penempatan mereka. Antara penempatan yang terlibat termasuklah di Java Road, Palembang Road, Kallang West Coast dan Kampong Bendong. Pada 27 Mei, Kesatuan Kebangsaan Anak-anak Bumiputera Singapura pula telah mengutus surat kepada Lee Kuan Yew agar kerajaan bertindak 
dengan adil terhadap orang Melayu untuk mengelakkan berlakunya kekacauan yang serius (Nik Anuar, 2001).

Pada 12 Julai, UMNO Singapura telah mengundang pertubuhan Melayu dan Islam seluruh Singapura untuk membincangkan 'Kedudukan Orang Melayu Singapura' di Panggung New Star, Pasir Panjang Road. Pemimpin-pemimpin yang berucap telah mengecam keras dasar kerajaan Lee Kuan Yew dan PAP (Pemimpin yang memberikan ucapan dalam perhimpunan ini termasuklah Syed Ja'afar Albar (mantan Ketua Penerangan UMNO), Hassan Adli (Naib Presiden PAS) dan Ali Haji Ahmad (Timbalan Setiausaha UMNO) (Nik Anuar, 2001). Perhimpunan yang dihadiri lebih seribu orang itu juga merayu Lee Kuan Yew agar memberi pembelaan yang sewajarnya kepada orang Melayu sebagai penduduk peribumi dan tidak meminggirkan mereka dalam arus pembangunan negara. Sebagai tindak balas, empat hari kemudian, 16 Julai, Lee Kuan Yew pula mengadakan perhimpunan bagi menjawab segala tohmahan yang dilemparkan terhadap dirinya dan PAP (Lau, 1998).

Sepanjang tempoh tersebut, Tun Razak dapat merasai suasana tegang sedang berlaku di Singapura. Pada 21 Julai, sambutan Maulidur Rasul di Singapura telah bertukar mejadi rusuhan kaum. Rusuhan ini telah mengorbankan dan mencederakan beratus-ratus orang sehingga kerajaan terpaksa membuat pengisytiharan perintah berkurung (Turnbull, 1977; Means, 1970). Sebaik sahaja menerima berita ini, Tun Razak sebagai pemangku Perdana Menteri bergegas terbang ke Singapura pada pagi 22 Julai. Semasa peristiwa ini berlaku, Tunku Abdul Rahman tiada di tanah air, sebaliknya berada di Amerika Syarikat, yakni selepas beliau menghadiri Persidangan Perdana Menteri Komanwel di London. Tun Razak terpaksa bersama-sama pemimpin Perikatan untuk membuat keputusan tanpa kehadiran Tunku Abdul Rahman. Beliau ke Singapura dengan diiringi oleh menteri-menteri kanan Persekutuan seperti Tan Siew Sin, Mohammed Khir Johari dan S. Manikavasagam. Keputusan mereka ke Singapura dapat ditafsirkan sebagai 'display of unity' (Lau, 1998).

Semasa di Singapura, Tun Razak dan pemimpin Persekutuan telah diberi taklimat berkaitan dengan rusuhan tersebut oleh ketua bahagian keselamatan, serta pemimpin-pemimpin politik, termasuk Lee Kuan Yew. Tun Razak juga meluangkan masa melawat mangsa di Hospital Besar Singapura dan mengunjungi tempat kejadian di kawasan Kampung Melayu, Geylang. Setelah itu, Tun Razak mengadakan pertemuan dengan pemimpin-pemimpin Melayu di Rumah Persekutuan (Lau, 1998).

Semasa sidang media, Tun Razak memaklumkan bahawa keadaan selepas rusuhan adalah terkawal, tetapi serius, perintah berkurung akan berterusan untuk seketika. Menurutnya lagi, punca rusuhan itu dikaitkan dengan seorang pengacau melontar sebiji botol ke arah perarakan itu (The Straits Times, 23 Julai 1964). Peristiwa ini bermula dengan seorang anggota polis Melayu ketika sedang mengawal perarakan Maulidur Rasul telah diserang oleh seorang ahli PAP. Sementara risalah-risalah haram yang diedarkan oleh Kesatuan Kemajuan Islam di kawasan Kampung Gelam juga dikaitkan dengan ketegangan yang mencetuskan rusuhan ini. Risalah ini antara lain menyeru orang Melayu supaya bersatu-padu dan menghancurkan kerajaan diktator PAP (Lee Kuan Yew, 2000; Lau, 1998). Semasa berucap di Radio Malaysia pula, Tun Razak telah melahirkan rasa kecewanya atas peristiwa yang berlaku itu dan menyeru semua kaum di Singapura dan Tanah Melayu agar bersatu padu untuk menjamin keharmonian negara.

"I can't help but think that there must be an insidious enemy responsible for all this. The procession to celebrate the birthday of the Prophet has been held year in and year out but never has there been anything untoward which has marred the procession. So why must it happen now? It is more than a coincidence that while we are having confrontation from Indonesia these communal clashes should have suddenly flared up" (Lau, 1998).

Walau bagaimanapun, peristiwa rusuhan kaum ini telah meninggalkan kesan besar ke atas kredibiliti dan ketokohan Tun Razak sebagai seorang pemimpin dan ahli politik. Beliau turut dituduh bersubahat dalam mencetuskan rusuhan itu (Shaws, 1976). Tuduhan ini tentulah datangnya daripada Lee Kuan Yew dan kerajaan PAP. Lee Kuan Yew menolak pandangan Tun Razak tentang punca sebenar 
rusuhan itu sepertimana dalam sidang medianya sebelum ini. Sebaliknya, Lee Kuan Yew mengaitkan punca rusuhan itu sepertimana berikut:

\begin{abstract}
"Seorang anggota Unit Simpanan Persekutuan (polis yang dihantar dari Semenanjung Malaysia) telah meminta satu kumpulan yang terkeluar daripada barisan perarakan supaya menyertai semula arus utama perarakan itu. Permintaannya itu diabaikan, malah dia sebaliknya diserang oleh kumpulan ini. Selepas itu satu siri kekacauan berlaku apabila lebih banyak kumpulan menjadi tidak terkawal dan menyerang orang-orang yang lalu lalang dan mereka yang tidak bersalah yang berdiri untuk melihat perarakan itu. Kekacauan itu merebak dengan cepatnya di merata kawasan Geylang. Menjelang jam 7.30 malam, kekacauan tercetus di kawasan bandar" (Lee Kuan Yew, 2000).
\end{abstract}

Di samping itu, Lee Kuan Yew turut menyalahkan Tun Razak sendiri kerana gagal mengawal puak pelampau dalam UMNO, khususnya Syed Ja'afar Albar dan akhbar Utusan Melayu dalam mengapiapikan sentimen perkauman sehingga tercetusnya rusuhan tersebut. Sementara diplomat asing di Kuala Lumpur dan Singapura juga lebih condong untuk menyalahkan UMNO sebagai punca kejadian rusuhan itu. Perkara ini dapat dilihat dalam laporan-laporan yang dikemukakan oleh Suruhanjaya Tinggi British di Kuala Lumpur, Jawatankuasa Risikan Bersama (Timur Jauh) bagi Jawatankuasa Ketua Turus British, Konsul-Jeneral Amerika Syarikat di Singapura, Arthur H. Rosen, Kedutaan Amerika Syarikat di Kuala Lumpur, Donald McCue dan Timbalan Suruhanjaya Australia di Singapura, W.B. Pritchett (Lee Kuan Yew, 2000; Lau, 1998). Malah Jabatan Ehwal Luar New Zealand dalam laporannya dengan jelas mengaitkan kelemahan pemimpin-pemimpin UMNO, termasuk Tun Razak sebagaimana berikut:

"It appears to us that Razak and other UMNO leaders did not act soon enough to curb the excesses of extremists like Ja'afar Albar and we (were) left in even more disturbing doubt by the reaction of the Federal Government to the riots" (Lau, 1998).

Ulasan yang sama nadanya, tetapi lebih pedas lagi berbisa dapat dilihat daripada kenyataan Timbalan Perdana Menteri Singapura, Goh Keng Swee yang begitu yakin dengan pembabitan Tun Razak secara langsung dalam peristiwa tersebut.

"Ini samalah dengan pengakuan bahawa beliau terlibat dalam kempen ini sepenuhnya untuk membangkitkan perasaan perkauman dan keagamaan Melayu di Singapura. Dan kemasukan Albar ke Singapura serta kempen-kempennya di Singapura dan sokongan yang diberikan kepada Utusan Melayu mendapat sokongan yang sepenuhnya daripada Razak. Ia tidak mungkin sebaliknya... Walau apapun kesannya, rusuhan itu berlaku, Razak terlibat, beliau memang jelas berniat untuk menyingkirkan Encik Lee daripada jawatannya. Itulah tujuan kempen Albar" (Goh,1982 dalam Nik Anuar, 2001).

Goh Keng Swee mengulas hasil pertemuannya dengan Tun Razak seminggu selepas rusuhan pada 2829 Julai 1964. Dalam ulasannya Goh Keng Swee mendakwa bahawa “....beliau (Tun Razak) telah memberi pendapatnya bahawa kekacauan tidak akan tercetus. Beliau mengaku bahawa beliau telah membuat kesilapan dalam pertimbangannya. Sekiranya beliau mengetahui kesannya, beliau tentunya akan mengambil tindakan" (Lee Kuan Yew, 2000).

Persoalannya, adakah kenyataan Goh Keng Swee itu benar? Sejauh manakah pula Tun Razak terlibat sebagai punca terjadinya rusuhan kaum tersebut? Berdasarkan petikan di atas, kenyataan itu merupakan suatu tafsiran atau andaian Goh Keng Swee sahaja yang tidak semestinya benar sama sekali. Sesungguhnya, sesuatu peristiwa itu tidak mungkin berlaku jika hanya sepihak sahaja yang bertanggungjawab dalam mencetuskan rusuhan tersebut. Pendek kata, Goh Keng Swee sudah tentu mempunyai agenda politiknya tersendiri dalam PAP dan Singapura terhadap kerajaan Pusat dan UMNO. Hal ini lebih jelas lagi jika ditinjau peristiwa yang berlaku itu saling berkaitan dengan tindak- 
tanduk dan tekanan yang tercetus daripada kedua-dua pihak semenjak penubuhan Malaysia lagi. Bagi Tun Razak, beliau sudah tentu mempunyai strategi politiknya yang tersendiri dalam menangani masalah Singapura dan sedapat mungkin menyingkirkan Lee Kuan Yew. Akan tetapi beliau bukannya menjadi dalang dalam mencetuskan peristiwa rusuhan kaum tersebut. Peristiwa rusuhan itu tercetus adalah lebih kepada 'internal problems' Singapura sepertimana yang telah dibincangkan sebelum ini. Natijahnya, perasaan kurang senang dengan pentadbiran Lee Kuan Yew dan PAP terus terbuku di hati Tun Razak dan pemimpin-pemimpin lain di peringkat Persekutuan.

Perasaan kurang senang Tun Razak itu dapat digambarkan semasa pertemuannya dengan Goh Keng Swee di Kuala Lumpur pada 28-29 Julai 1964 (PREM 11/4904, Kuala Lumpur - CRO, 22 Julai 1964). Tun Razak mengemukakan dua pilihan untuk menyelesaikan masalah di antara Kuala Lumpur dengan Singapura. Pertama, pembentukan kerajaan campuran, yakni terdapat wakil PAP dalam kabinet Persekutuan, tetapi dengan syarat Lee Kuan Yew hendaklah melepaskan jawatannya sebagai Perdana Menteri. Lee Kuan Yew juga dicadangkan agar memegang jawatan di PBB dan selepas tiga tahun akan dikaji semula kedudukannya itu. Kedua, mengadakan perjanjian politik di antara kedua-dua kerajaan untuk tidak campur tangan dalam urusan politik negeri atau wilayah masing-masing. Tun Razak meminta PAP menguruskan hal ehwal masyarakat Melayu di Singapura melalui Ketua Penerangan UMNO, Muhammad Khir Johari. PAP juga diingatkan tidak mempengaruhi orang Melayu supaya menyokong PAP. Sementara "musuh" PAP, Syed Ja'afar Albar tidak akan disingkirkan atau didakwa, dan Utusan Melayu akan dikawal sepenuhnya oleh Tun Razak. Walau bagaimanapun, cadangan Tun Razak itu ditolak oleh Lee Kuan Yew dan PAP kerana dianggap tidak praktikal (Nik Anuar, 2001; Lee Kuan Yew, 2000).

Hubungan yang semakin runcing di antara kerajaan pusat Kuala Lumpur dengan Singapura telah mengundang rasa bimbang kerajaan British. Dalam usaha menyelamatkan Malaysia, British berusaha menjadi 'orang tengah' untuk meleraikan masalah hubungan kerajaan Pusat, Kuala Lumpur dengan Singapura. Akan tetapi usaha tersebut masih gagal dan menemui jalan buntu. Usaha ini telah dilakukan oleh Perdana Menteri British, Sir Alec Douglas Home yang mengadakan rundingan dengan Tunku Abdul Rahman dan Lee Kuan Yew (Lee Kuan Yew, 2000; Nik Anuar, 2001; Lau, 1998). Sebaliknya, hubungan Kuala Lumpur-Singapura bertambah tegang apabila Lee Kuan Yew mengumumkan hasratnya untuk menubuhkan pakatan parti politik dengan tujuan menentang Perikatan dalam pilihan raya umum keempat pada tahun 1969. Susulan itu, Malaysian Solidarity Convention (MSC) ditubuhkan pada 9 Mei 1965. United Democratic Party dan Sarawak United People's Party (SUPP) adalah pertubuhan yang turut terlibat dalam penubuhan MSC (Muhamed Noordin Sopiee, 1974; Albert Lau, 1998). Slogan 'Malaysian Malaysia' dijadikan dasar perjuangan MSC. Lee Kuan Yew berikrar akan mewujudkan pemerintahan yang adil dan sama rata atas semangat 'Malaysian Malaysia'. (Dayu, Mohd Sohaimi \& Yusten, 2015) Perlembagaan negara akan dikaji semula bagi membasmi sebarang peruntukan yang dianggap bersifat diskriminasi terhadap kaum tertentu. Malahan Lee Kuan Yew mempersoalkan status orang Melayu sebagai penduduk pribumi negara ini. Sebagai Timbalan Perdana Menteri, Tun Razak memandang serius dengan penubuhan MSC yang berjuang bukan sekadar untuk menjatuhkan Perikatan, tetapi untuk menghapuskan hak istimewa orang Melayu yang termaktub dalam perlembagaan negara (Mohamed Noordin, 1974; Fletcher, 1969).

Pada bulan Jun 1965, perdebatan di Dewan Rakyat ialah kemuncak kekeruhan hubungan antara kerajaan Persekutuan dengan Singapura. Di Dewan Rakyat, Lee Kuan Yew membawa usul yang tidak pernah dilakukan sebelum ini apabila beliau meminta pindaan ke atas ucapan Yang Dipertuan Agung. Beliau menyatakan kekesalannya apabila Yang Dipertuan Agung tidak menyebutkan tentang kepentingan perjuangan 'Malaysian Malaysia'. Di samping itu, beliau melontarkan perasaan tidak puas hati dengan titah Yang Dipertuan Agong berkaitan dengan 'threat from within' (ancaman dari dalam). Beliau membuat tanggapan bahawa maksud di sebalik ancaman itu adalah dirinya dan PAP. Bermula dari sini, sidang Dewan Rakyat menjadi hangat dan panas dengan perbahasan yang bersifat sensitif dan menyentuh sentimen perkauman. Antaranya termasuklah hubungan Kuala LumpurSingapura, masa depan PAP dan Perikatan, serta kedudukan dan hak kaum Melayu dan Cina di Malaysia (Nik Anuar, 2001). 
Semasa menggulung perbahasan, Tun Razak telah membidas segala hujah yang dikemukakan oleh Lee Kuan Yew secara matang dan rasional. Tun Razak memulakan dengan menolak tuduhan Lee Kuan Yew bahawa yang dimaksudkan dengan 'threat from within' itu adalah PAP. Sebaliknya, beliau menjelaskan secara panjang lebar kenyataan tersebut dengan ancaman dalaman akibat pengaruh Komunis dan konfrontasi Indonesia terhadap Malaysia. Beliau juga menolak tuduhan Lee Kuan Yew bahawa kerajaan Persekutuan berusaha mewujudkan pemerintahan Melayu di Malaysia dengan menindas kaum-kaum lain ataupun menganggap negeri-negeri lain itu sebagai 'inferior'.

"That was why he came to see the Prime Minister some time ago and put forward a proposal that his party should share in the administration of this Government in place of the MCA. This idea was wholly unacceptable, in fact, most objectionable to the mind of an honest and loyal leader. The MCA has been our true friends indeed and, together with the MIC, we have worked for the independence of Malaya, which led eventually to the independence of the other States, which now make up Malaysia. It is unthinkable that the Prime Minister could discard the MCA for the PAP. He has always regarded the MCA as a true friend of UMNO and as a partner who, together with the MIC, has worked for the well-being, prosperity and happiness of this country... This cannot be said of the PAP. As has often been said in this House in the debate, Mr. Lee Kuan Yew, in fact, thinks in terms of the Chinese, or a small section of the Chinese in Singapore, and the only Government which will be acceptable to him is one in which he can have a big say and a big share, and ultimately a Government which he alone can have a say without resort to parliamentary democracy. Now, sir, since his proposal to replace MCA is not acceptable to the Prime Minister, he has switched on to his new insidious plan of a Malaysian Malaysia. In other words, a breakup of Malaysia as constituted under the Agreement signed in London" (Penyata Perbahasan Dewan Rakyat, 3 Jun 1965).

Selain isu 'Malaysian Malaysia', Tun Razak turut membangkitkan muslihat Lee Kuan Yew di sebalik rancangannya itu boleh menghancurkan Persekutuan Malaysia.

"His plan is insidious. Now, sir, Honourable Members can now understand the imputation, when he said that there are some who want secession. We have never talked about secession, at least not by the Prime Minister and members of the Government. He also said that probably the people of Penang, Sabah, Sarawak and Singapore and Malacca could come together. This is what we read in the newspaper, and this is what we heard Radio Singapore said. In short, he has suggested that Malaysia must be broken up into two: one is, as he stated, Malay Malaysia, and the other one Mr Lee Kuan Yew's Malaysia, or Straits Settlement Malaysia - whatever he wants to call it. It is clear" (Penyata Perbahasan Dewan Rakyat, 3 Jun 1965).

Tun Razak turut mempertikaikan tuduhan Lee Kuan Yew yang menganggap kerajaan pusat mengamalkan dasar diskriminasi dan tidak demokratik. Antara lain yang menarik dikemukakan oleh Tun Razak dalam membidas kenyataan Lee Kuan Yew itu sepertimana berikut:

"We have them six weeks in which to campaign throughout the country and put their views to the people, while in Singapore, the PAP only allowed other political parties nine days to prepare for the elections. Is this following the true spirit of democracy?" (Penyata Perbahasan Dewan Rakyat, 3 Jun 1965).

Tun Razak juga kurang senang dengan tindakan Malaysia Solidarity Convention (MSC) yang mempertikaikan perkara 153 dalam perlembagaan negara. Contohnya, bahasa kebangsaan, Tun Razak dengan tegas menjawab isu yang dibangkitkan sepertimana berikut: 
"how could the Malay language help to uplift the standards of living of the Malay?' Of course, he knows as well as we do that language has nothing to do with the standards of living of the people. Language is the soul of the nation'Bahasa Jiwa Bangsa'. This is not a matter which can be measured in terms of wealth, or of the standard of living or of material advantage. He knows this, and we all know this. Why make such a remark, if one sincerely believes in promoting the National language, in making it the language for unity of our people?" (Penyata Perbahasan Dewan Rakyat, 3 Jun 1965).

Pada akhir penggulungan, Tun Razak dengan lantang menyalahkan Lee Kuan Yew atas kekalutan politik dalam negara dan tindak tanduknya telah menguntungkan Indonesia. Beliau menambah bahawa, "Lee was playing dangerous game and had embarked on neckless adventure. If despite alliance government's belief in, and work for, racial harmony trouble was to break out they must hold him fully responsible" (Penyata Perbahasan Dewan Rakyat, 3 Jun 1965). Walau apa pun alasan Lee Kuan Yew, Tun Razak sebagai Timbalan Perdana Menteri dapat memberikan hujah yang bernas dan meyakinkan untuk ahli-ahli sidang parlimen tersebut. Hal ini juga mencerminkan luahan perasaan yang terbuku di hati Tun Razak dan pemimpin-pemimpin lain di dalam Perikatan. Tun Razak mahupun pemimpin-pemimpin dalam Perikatan ternyata amat kecewa dengan sikap dan tindak tanduk Lee Kuan Yew dan PAP itu (Fletcher, 1969; The Straits Times, 11 Mei 1965).

Semasa Tunku Abdul Rahman menghadiri Mesyuarat Menteri-Menteri Komanwel di London, Lee Kuan Yew mengemukakan hasrat untuk bertemu dengan Tun Razak bagi meleraikan konflik yang semakin meruncing antara kerajaan Persekutuan dengan Singapura. Namun begitu, Pemuda UMNO telah mendesak agar Tun Razak menangguhkan pertemuan itu sehingga Lee Kuan Yew meminta maaf kepada bangsa Melayu (Berita Harian, 10 Julai 1965). Akan tetapi gesaan Pemuda UMNO itu ditolak oleh Tun Razak. Beliau menjelaskan bahawa kedudukannya sebagai Pemangku Perdana Menteri harus bersedia untuk bertemu dengan sesiapa sahaja dalam kalangan pemimpin kerajaan, termasuklah Lee Kuan Yew. Malah beliau mengharapkan dengan pertemuan ini sekurang-kurangnya akan dapat menyelami hasrat sebenar Lee Kuan Yew (Ibrahim, 1981). Nyatalah Tun Razak mempunyai pendirian tersendiri dengan tidak tunduk kepada tekanan daripada pihak dalaman, UMNO.

Pada 29 Jun 1965, Tun Razak ke Singapura untuk bertemu dengan Lee Kuan Yew. Mengikut catatan Tun Razak, Lee Kuan Yew bukan bertujuan untuk mencari jalan penyelesaian, tetapi mendesak supaya puak pelampau dalam UMNO mesti disingkirkan sebelum memulihkan hubungan antara Singapura dengan kerajaan Persekutuan. Tun Razak telah menolak tuduhan Lee Kuan Yew tersebut, sebaliknya beliau dengan tegas mempertahankan UMNO sebagai sebuah pertubuhan yang berwibawa dan bertertib. Semua pemimpin dan ahli-ahli UMNO patuh kepada pucuk pimpinan dan dasar perjuangan UMNO. Tun Razak dengan tegas mengingatkan Lee Kuan Yew sekiranya ingin bekerjasama hendaklah beliau menaruh kepercayaan kepada pucuk pimpinan UMNO, yakni Tunku Abdul Rahman (Nik Anwar, 2001). Seterusnya Tun Razak meminta Lee Kuan Yew memberi jaminan supaya beliau dan rakan-rakannya tidak akan membuat kenyataan yang menyakitkan hati orang Melayu dan mencampuri urusan dalaman UMNO. Akan tetapi Lee Kuan Yew enggan memberi jaminan tersebut. Natijahnya, perjumpaan itu tidak membawa sebarang makna kepada kedua-dua pihak dalam menyelesaikan konflik antara kerajaan Persekutuan dengan kerajaan Singapura.

Selang beberapa hari kemudian, Alex Josey, pembantu Lee Kuan Yew telah diusir dari Semenanjung kerana pembabitannya dalam hal ehwal politik Malaysia dan melakukan pelbagai tindakan yang boleh memecahbelahkan perpaduan antara kaum (Berita Harian, 14 Julai 1965; Nik Anuar Nik Mahmud, 2001). Ekoran pengusiran Alex Josey dari Malaysia, PAP menyebarkan pula dakyah kononnya kerajaan Persekutuan akan menahan dan menangkap Lee Kuan Yew. Berita angin itu dinafikan sekeras-kerasnya oleh Tun Razak dengan menganggapnya sebagai tindakan yang tidak bertanggungjawab.

"Tuduhan PAP itu terlalu liar dan jahat untuk diulas. Rakyat negeri ini tahu bahawa kerajaan Perikatan adalah sebuah kerajaan yang bertanggungjawab, adil dan saksama. Kami tidak ke sana sini menangkap orang tanpa sebab dan alasan 
DOI: https://doi.org/10.47405/mjssh.v5i12.589

yang mencukupi. Kami menyokong dan menegakkan prinsip demokrasi berparlimen dan pemerintahan menurut undang-undang. Hanya mereka yang bertindak bertentangan dengan undang-undang negara sahaja yang harus menerima akibat-akibat perbuatan mereka" (Berita Harian, 22 Julai 1965).

Sebagaimana Tun Razak, Tunku Abdul Rahman juga memberi jaminan bahawa tidak akan menahan Lee Kuan Yew (Berita Harian, 22 Julai 1965). Walaupun begitu, Tun Razak mengingatkan pemimpin PAP, khususnya Lee Kuan Yew supaya tidak membangkitkan lagi isu-isu perkauman yang boleh menggugat keharmonian dan keamanan negara ini (Mohd. Sohaimi, Dayu \& Budi, 2011; Dayu, Mohd Sohaimi Budi \& Yusten, 2015; Mohd. Sohaimi et al., 2020).

Sementara itu, Tunku Abdul Rahman turut dimaklumkan tentang kegagalan rundingan Tun Razak-Lee Kuan Yew itu. Tunku yang sedang menerima rawatan di London telah membuat keputusan muktamad untuk menyingkirkan Singapura dari Malaysia (Tunku Abdul Rahman, 1997). Pada 1 Julai 1965, Tunku Abdul Rahman mengarahkan Tun Razak supaya berbincang dengan menteri-menteri kanan lain tentang keputusannya itu. Tun Razak mengadakan mesyuarat tertutup dengan anggota kabinet kanannya, iaitu Dato' Dr. Ismail Abdul Rahman, Tan Siew Sin dan V.T. Sambanthan. Mesyuarat telah memutuskan bahawa kerajaan Pusat mempunyai dua pilihan untuk mengatasi masalah Lee Kuan Yew dan Singapura. Pertama, menggunakan kuasa darurat dengan mengambil tindakan secara kekerasan terhadap pimpinan PAP; atau kedua, memberikan kemerdekaan kepada Singapura. Mereka mencapai kata sepakat bahawa Singapura mesti disingkirkan dari Malaysia (Nik Anuar, 2001).

Pada 13 Julai 1965, Tun Razak memaklumkan kepada Goh Keng Swee, Menteri Perdagangan dan Industri Singapura tentang keputusan kerajaan Malaysia untuk berpisah dengan Singapura. Goh Keng Swee telah memaklumkan keputusan Kuala Lumpur itu kepada Lee Kuan Yew. Kabinet Lee Kuan Yew telah bersidang dan dengan perasaan yang berat terpaksa bersetuju sepertimana kehendak Kuala Lumpur untuk kebaikan kedua-dua pihak. Persetujuan ini telah dimaklumkan kepada Tun Razak pada 20 Julai 1965. Pada masa yang sama Tun Razak memaklumkan kepada Tunku Abdul Rahman tentang kesediaan Singapura untuk menerima keputusan tersebut (Nik Anuar, 2001).

Pada 9 Ogos, Tunku Abdul Rahman membawa usul 'Pemisahan' Singapura dari Malaysia di Parlimen. Semasa mengisytiharkan perpisahan Singapura, Tunku dengan masyghul memperkatakan tentang 'sebuah Kerajaan Negeri yang tidak lagi memberikan, bahkan sedikit pun taat setia kepada Kerajaan Pusat (Penyata Sidang Parlimen Khas, 9 Ogos 1965). Abdul Razak bin Hussein (1966) dalam perbahasan usul ini telah mengambil kesempatan untuk memberikan penjelasan dengan menegaskan bahawa "Kita terpaksa mengeluarkan Singapura dari Malaysia - dan ini-lah sa'at yang sunggoh bersejarah, sungoh pun kita berasa sedeh dan dukachita kerana satu negeri telah terpaksa keluar, tetapi kita gembira kerana kita telah dapat menyingkirkan duri dari dalam daging kita". Sesungguhnya, dengan perumpamaan, 'duri dalam daging' itu jelas menggambarkan kemelut yang amat hebat terpaksa ditanggung oleh kerajaan pusat, Kuala Lumpur selama Singapura dalam Malaysia. Penyingkiran Singapura merupakan keputusan terbaik yang terpaksa dilakukan oleh kerajaan pusat untuk menjamin keharmonian dan kemakmuran negara. Selang tiga minggu selepas Singapura disingkirkan dari Malaysia, Tun Razak dalam ucapan Sempena Ulang Tahun Kedua Penubuhan Malaysia telah memberikan penjelasan punca Singapura dipisahkan dari Malaysia sepertimana berikut:

"However, just a little more than three weeks ago, it was found necessary by both
the Central Government and the Singapore Government that Singapore should be
separated from the rest of Malaysia. It was a sad and heartbreaking decision, but
the leaders of the two countries were convinced that this was the only solution in
the circumstances. Since the establishment of Malaysia, it was found that
Singapore could not fit in into the Federation and the Central Government and the
Government of Singapore, due to many reasons have found it impossible to work
together. Lately there was almost a deadlock and what is more the differences
between the political leaders in Singapore and in Kuala Lumpur have brought
racial tension. The leaders of the PAP Government in Singapore had accused the 
Central Government of favoring one race against another and that it was a Malaydominated Government. These unfounded criticisms spread throughout the country and overseas have led to racial tension and racial troubles" (Special message from the Deputy Prime Minister Commemorating the Second Anniversary of the Birth of Malaysia on 28th August 1965, dalam Ucapan-ucapan Tun Haji Abdul Razak bin Hussein, 1965).

Sungguhpun Singapura dipisahkan dari Malaysia, tetapi Tun Razak tetap mengalu-alukan kerjasama di antara kedua-dua negara, khususnya dalam bidang keselamatan, pertahanan, perdagangan dan industri.

\section{Kesimpulan}

Singapura dalam Persekutuan Malaysia hanya dapat bertahan kurang dari dua tahun. Penyingkiran ini terpaksa dilakukan kerana wujudnya sentimen perkauman sehingga menimbulkan ketegangan dan rusuhan yang boleh mengancam keselamatan negara. Berdasarkan analisis bahan sejarah yang telah dilakukan, adalah didapati bahawa keberadaan Singapura dalam Persekutuan Malaysia telah menyumbang kepada peningkatan masalah perkauman di negara ini. Ini menyebabkan Tun Razak menegaskan bahawa Singapura adalah 'umpama duri dalam daging' dalam Persekutuan Malaysia. Sejajar dengan perumpamaan tersebut maka akhirnya ketidaksenangan para pemimpin negara terhadap Singapura semakin berkembang. Keadaan ini seterusnya membawa kepada usul menyingkirkan Singapura dari Persekutuan Malaysia.

Kemuncak kepada usul tersebut ialah penyingkiran Singapura pada tahun 1965 dari Persekutuan Malaysia. Sejak itu, Singapura bukan lagi sebahagian daripada Persekutuan Malaysia. Namun apa yang menarik perhatian dalam hal ini ialah peranan signifikan yang dimainkan oleh Tun Abdul Razak dalam penyingkiran Singapura yang bertujuan memastikan kelestarian keharmonian hubungan kaum di negara ini. Adalah ditegaskan bahawa keputusan tersebut adalah amat wajar dilakukan bagi kelangsungan Persekutuan Malaysia.

\section{Penghargaan}

Kertas kerja ini telah dibentangkan dalam Persidangan Sejarah Malaysia dan Borneo, Universiti Malaysia Sabah, Kota Kinabalu, 17 Mei 2016.

\section{Rujukan}

Abdul Razak Hussein. (1966). Pemisahan Singapura dari Malaysia. Dalam UMNO 20 Tahun. Kuala Lumpur: Ibu Pejabat UMNO.

Albert Lau. (1998). A Moment of Anguish: Singapore in Malaysia and the Politics of Disengagement. Singapore: Times Academic Press.

Ahmad Tarmizi Abdul Rahman, Romzi Ationg \& Nurul Ain Zulhaimi. (2017). A paradigm shift in understanding mixed method research: A Malaysian perspective. Journal of Advanced Research in Social and Behavioural Sciences, 9(1), 46-56

Berita Harian. (10 Julai 1965).

Berita Harian. (22 Julai 1965).

Berita Harian. (14 Julai 1965).

Chan Heng Mee. (1971). Singapore: The Politics of Survival 1965-1967. Singapore: Oxford University Press.

Dayu Sansalu, Mohd Sohaimi Esa, Yusten Karulus \& Budi Anto Mohd Tamring. (2015). Eksplorasi Hubungan Etnik. Kuala Lumpur: Penerbit Sasbadi.

Gullick, J.M. (1969). Malaysia. London: Ernest Benn Ltd.

Ibrahim Mahmood. (1981). Sejarah Perjuangan Bangsa Melayu: Suatu Penyingkapan Kembali Sejarah Perjuangan Bangsa Melayu Menuju Kemerdekaan. Kuala Lumpur: Pustaka Antara. 
Fletcher N.M. (1969). The Separation of Singapore from Malaysia. New York: Cornell University, Ithaca.

Lee Kuan Yew. (2000). Kisah Singapura: Memoirs of Lee Kuan Yew. Singapore: Press Holdings and Times Edition.

Means, G.P (1970). Malaysian Politics. London: Hodder and Stoughton.

Mohamed Noordin Sopiee. (1974). From Malayan Union to Separation: Political Unification in the Malayan Region 1945-46. Kuala Lumpur: Penerbit Universiti Malaya.

Malaysia. (1965). The Election Commission, Report on the Parliamentary (Dewan Rakyat) and State Legislative Assembly General Elections, 1964 of the States of Malaysia. Kuala Lumpur: Jabatan Chetak Kerajaan.

Mohd. Sohaimi Esa. (2011). Sumbangan Tun Abdul Razak dalam membina hubungan MalaysiaIndonesia. Journal Jabatan Sejarah Universiti Malaya, 11, 397-216.

Mohd. Sohaimi Esa, Dayu Sansalu \& Budi Anto Mohd Tamring (2011). Hubungan Etnik: Kelangsungan Pembinaan Negara Bangsa. Puchong: Penerbitan Multimedia.

Mohd. Sohaimi Esa, Romzi Ationg, Suraya Sintang, Abang Mohd. Razif Abang Muiz, Mohd Azri Ibrahim \& Sirahim Abdullah. (2020). Youth Voluntary Organization, Leadership and Intergroup Relationship in Sabah, Malaysia: A Preliminary Discussion. Solid State Technology, 63(6), 722730 .

Mohd. Sohaimi Esa, Romzi Ationg, Siti Aida Lokin, Sirahim Abdullah, Abang Mohd. Razif Abang Muiz \& Mohd. Azri Ibrahim. (2020). Linking Leadership Ethics and Intergroup Relationship through the Revision of Leadership Theories and Intergroup Relationship. Solid State Technology, 63(6), 742-752.

Nik Anuar Nik Mahmud. (2001). Duri dalam Daging: Singapura dalam Malaysia. Kuala Lumpur: Persatuan Sejarah Malaysia.

Ratnam, K.J. \& Milne, R.S. (1967). The Malayan Parliamentary Election of 1964, Singapore: University of Malaya Press.

Records of the Prime Minister Office (PREM)11/4904, Kuala Lumpur - CRO, 22 Julai 1964. National Archives of London (Public Record Office, Kew Garden).

Romzi Ationg, Mohd. Sohaimi Esa \& Mohd. Azri Ibrahim. (2020). Menyingkap Polemik Peralihan Kuasa Secara Luar Biasa Mengikut Perspektif Demokrasi Berparlimen. Malaysian Journal of Social Sciences and Humanities (MJSSH), 5(11), 43-53.

Romzi Ationg, Mohd Azri Ibrahim, Mohd. Sohaimi Esa \& Madiyem Layapan. (2020). Analisis Pola Pengundian dan Senario Politik Semasa di Malaysia Era Pasca Pilihan Raya Umum (PRU) Ke-14 Berdasarkan Pilihan Raya Kecil P186 Sandakan, Sabah. Malaysian Journal of Social Sciences and Humanities (MJSSH), 5(5), 60-71.

Romzi Ationg. (2017). Federal Political Elites and the Expansion of Ethnic Politics to the Periphery State of Sabah in Malaysia. The Australian National University, Canberra, Australia.

Shaw, W. (1976). Tun Razak: His Life and Times. Kuala Lumpur: Longman Malaysia.

Straits Times. (4 September 1963).

The Malay Mail. (30 September 1963).

The Sunday Times. (29 September 1963).

The Straits Times. (2 Mac 1964).

The Straits Times. (11 Mei 1965).

Tunku Abdul Rahman. (1977). Looking Back: Monday Musings and Memories. Kuala Lumpur: Pustaka Antara.

Turnbull, C.M. (1977). A History of Singapore: 1819-1975, Kuala Lumpur: Oxford University Press.

------ (1975). Ucapan-ucapan Tun Haji Abdul Razak Bin Hussein 1965. Kuala Lumpur: Arkib Negara Malaysia dan Jabatan Perdana Menteri.

------- (1965). Penyata Sidang Parlimen Khas (9 Ogos 1965). Kuala Lumpur: Jabatan Chetak Kerajaan.

------- (1965) Penyata Perbahasan Dewan Rakyat (3 Jun 1965). Kuala Lumpur: Jabatan Chetak Kerajaan.

------ (13 Jun 1963). Records Created or Inherited by the Dominions Office, and of the Commonwealth Relations and Foreign and Commonwealth Offices, (DO 169/19, No. 33/45/1, Selkirk to Secretary of State for the Colonies, (Telegram no. 402). National Archives of London (Public Record Office, Kew Garden). 
DOI: https://doi.org/10.47405/mjssh.v5i12.589

------ (June-July 1963). Records Created or Inherited by the Dominions Office, and of the Commonwealth Relations and Foreign and Commonwealth Offices, (DO 187/30, Talks in London on the Establishment of the Federation of Malaysia. National Archives of London (Public Record Office, Kew Garden).

-- (2 September 1963). Records of the Prime Minister Office (PREM) 11/4351, Kuala Lumpur Singapore. National Archives of London (Public Record Office, Kew Garden).

-- (June-July 1963). Records Created or Inherited by the Dominions Office, and of the Commonwealth Relations and Foreign and Commonwealth Offices, (DO 187/30, Talks in London on the Establishment of the Federation of Malaysia. 